There has been a vision that the service would be mainly consultant provided since the Spens Committee report in $1948 .^{8}$ Through several reports since, that vision has remained unaltered and unachieved. ${ }^{3410}$ Although there have been some modest variations, the ratio of junior doctors to consultants now is much the same as it was at the inception of the health service. ${ }^{11}$ The working group's report makes little reference to the strategic plans for the NHS or to the reforms. Both will affect the need for doctors and how consultants will be expected to work. One of the reasons why manpower planning has failed is that it has never been integrated with other NHS plans. This has left most medical activity "unmanaged" and ensured a continuing contradiction between professional aspirations to enhance the medical career structure and attempts to manage the health service in ways that accord primacy to other NHS goals. ${ }^{12}$

Why this happens warrants critical evaluation. For a profession that places such emphasis on its ability to examine evidence scientifically it is remarkable that it should manage its own affairs on the basis of opinion rather than testable fact. Dr Alistair Scotland, who was a member of the working party, asked some pertinent questions about consultant working patterns in $1990 .{ }^{13} \mathrm{His}$ questions remain unanswered, and, unless they are, Calman's report will not be successful as consultants at local level again react instinctively and protectively against changes in their working patterns and increases in their number. Similarly, ministers and managers may refuse to implement plans that are expensive and do not seem linked to the overall strategic intent and direction of the health service.
Consultation on the report continues until July. There may be more work to do-as some claim-but it would be a great pity if Calman's report were to go the way of the Spens, Platt, Todd, and Short reports and fail on the rocks of unimaginative professional resistance and unimaginative managerial restraint.

Gwent Community NHS Trust,

Llanfrechfa,

Gwent NP44 8YN

Canterbury and Thanet NHS Trust,

St Martin's Hospital,

Canterbury,

Kent CT1 1TD

1 Department of Health. Hospital doctors: training for the future. The report of the working group on specialist medical training. London: $\mathrm{DoH}, 1993$.

Beecham L. Specialist training may be overhauled. BMF 1993;306:1287-8.

3 Social Services Committee. Fourth reporn. Medical education with special reference to the number of doctors and their career structure in hospitals. London: HMSO, 1981. (Short report.)

4 Department of Health. Hospital medical staffing - achieving a balance. Plan for action. London DoH, 1987.

5 Brearley S. Specialist medical training and Europe. BMF 1992;305:661-2.

6 Andersen TF, Mooney G, eds. The challenges of medical practice variations. London: Macmillan, 1990.

7 Department of Health. Dear colleague. Consultation on report of working group on specialist medical education. London: DoH, 1993. (KK/00923.04.)

Interdepartmental Working Committee on the Remuneration of Specialists. Report. London: HMSO, 1948. (Spens report.) (Cmnd 7420.)

9 Joint Working Party on the Medical Staffing Structure in the Hospital Services. Report. London: HSO 1961. (Plat the Medic 10 Royal Commission on Medical Education. Report. London: HMSO, 1968. (Todd report.) (Cmnd

11 Ham C. Policy making in the National Health Service. London: Macmillan, 1981.

12 Long AF, Mercer G. Health manpower: planning, production and management. London: Croom Helm, 1987

13 Scotland A. Consultant oligarchy or workers' cooperative? Br $f$ Hosp Med 1990;44:152.

\title{
Annual reports of directors of public health
}

\section{We need to agree their aims and evaluate their effectiveness}

Annual public health reports, to be written by directors of public health, were reintroduced following the Acheson report. ${ }^{1}$ They were designed to "Inform each district health authority ... . about the health of the population for which they are responsible and ... to be an integral component of the health planning and contracting cycle."2 Acheson suggested that the report should be "based on the professional work and judgment of the director of public health and ... make an important contribution to the accountability of the health authority to the people they serve."1

Most directors of public health have now produced several annual reports, and it may be time to assess how well these have measured up to the original aims, especially since the NHS has changed dramatically since the Acheson report. Producing reports is costly in terms of both money and manpower, and so far there is little evidence of their effectiveness. Those assessments that have been undertaken have been predominantly concerned with the contents of the reports. ${ }^{34}$ A specific example is the King's Fund initiative, which, despite a lack of criteria for assessing even their content, offers a prize for the "best."

The Faculty of Public Health Medicine has suggested several functions that could be served by the annual public health report; these include challenging conventional beliefs about health and disease and identifying opportunities for health authority action. ${ }^{2}$ There is no evidence, however, that these functions have been widely accepted either by directors of public health or by their health authorities, and no attempt has been made to undertake a widespread review of the impact of reports measured against such goals.

In the context of the reformed NHS there seem to be three components to the objectives of annual public health reports as originally envisaged by Acheson ${ }^{1}$ : (a) that annual reports should influence commissioning and be integral to the strategic planning programme; $(b)$ that they should reflect the independent judgment of the directors of public health; and (c) that they should enhance the accountability of health authorities to the population they serve.

The common dilemma arising from such objectives is how directors of public health can maintain an independent view in their reports while at the same time ensuring that reports are "owned" by commissioning authorities. If authorities do not feel they own the report they are less likely to adopt its? recommendations and thus the report is less likely to be effective. The principle that a board member with corporate responsibilities should produce an independent report is unusual and may not be readily accepted by other directors of health authorities. ${ }^{5}$ Because health authorities normally finance the annual report they may also be reluctant to relinquish all editorial control.

Against this is the belief that directors of public health must maintain the right to produce an independent report to help fulfil their role as advocate for the public health. ${ }^{46}$ Such autonomy is essential to ensure that public health issues outside the health authority's commissioning priorities are aired and that a broader view is offered of the way in which the 
health of the population may be improved. Without this independence such issues may be lost in the present political and economic climate of the NHS and with the strong financial orientation of managers. ${ }^{7}$

The old style reports of medical officers of health were criticised for simply rehashing routine statistics rather than covering fresh ground and showing improvements in health. They became "stereotyped and stale . . . an annual chore of questionable value." If directors of public health are to avoid this fate for their annual reports they need to evaluate their reports' impact against widely agreed national and local criteria. This does not mean that the content and format of reports should be rigidly dictated but simply that there should be agreement about their purpose and objectives. The tension between independence and corporate ownership must either be resolved or be used constructively to achieve debate for the overall benefit of the public health.

Another review of the public health function within the NHS has been announced ${ }^{89}$; we hope that this review will consider the function of annual reports and how to evaluate their effectiveness; the issue of the independence of reports must also be addressed. Public health medicine has long considered itself to have a legitimate role in measuring clinical outcomes and the effectiveness of health care; it should not forget to look in its own back yard.

IAN S WATT

Senior registrar in public health medicine

SUE L IBBOTSON

Senior registrar in public health medicine

CAROL NICHOLSON

Epidemiologist

East Riding Health Authority,

Hull HU2 8TD

1 Department of Health and Social Services. Public health in England: the report of the committee of inquiry into the future development of the public health function. London: HMSO, 1988. (Cmnd 289; Acheson report.)

2 Pencheon D, Gray, eds. Health measurement toolbox. 3rd ed. London: Faculty of Public Health Medicine, 1991.

Department of Health. Annual repors on the health of the population: content review. London: DoH, 1990. (EL(90)P/8.1.)

4 Gair R, Li Chee Lan L, McKee M, Parikh C, Weinberg J. Criteria for audit of annual reports on the public health: do they exist? I Public Health Med 1992;14:169-72.

5 Freemantle N, Watt IS, Mason J. Developments in the purchasing process in the NHS: towards an explicit politics of rationing. Public Administration (in press).

explicit politics of rationing. Public Administration (in press).
6 What's new in public health? [Editorial.] Lancet 1991;337:1381-3.

7 Pollitt C, Harrison S, Hunter DJ, Marnoch G. General management in the NHS: the initial impact. Public Administration 1991;69:61-83.

8 Department of Health. On the state of the public health: the annual repon of the chief medical officer of the Department of Health for the year 1991. London: HMSO, 1992.

9 Department of Health. Review of public health guidance to the NHS needed says Brian Mawhinney. London: DoH, 1993. (Press release No H93/509.)

\section{How should new treatments for benign prostatic hyperplasia be assessed?}

\section{Symptomatic measurements are not enough}

Benign prostatic hyperplasia may present in several ways. ${ }^{1}$ Some patients seek treatment for clearly obstructive symptoms, others for irritative symptoms (such as frequency, nocturia, and urgency) resulting from secondary bladder instability. In some, chronic retention develops insidiously and if associated with high bladder pressure may lead to hydronephrosis and obstructive uraemia. Acute retention commonly presents in men not previously worried by urinary symptoms.

Measuring the outcome of treatment for benign prostatic hyperplasia has not previously been of great interest. Indeed, it must be admitted that urologists have been cavalier in assessing the benefits of transurethral prostatectomy. A quick follow up interview, to see whether the patient is happy with the symptomatic outcome of his treatment, is the most that is usually done, and some urologists even question the need for routine postoperative follow up. For a man who has had retention, to be able to pass urine spontaneously is a successful outcome, easy to assess. In most cases the preoperative problem is one of troublesome symptoms rather than life threatening morbidity; if after surgery the patient is happy perhaps all is well. Unfortunately, a satisfactory outcome from transurethral prostatectomy is not invariable, a reflection more of difficulties in selection for treatment than of inadequacies of the treatment itself. ${ }^{2}$

Things are no longer so simple. Many new treatments have now been proposed for benign prostatic hyperplasia including drugs, prostatic hyperthermia, stents, balloon dilatation, and laser prostatectomy. Elsewhere in this journal Bdesha and colleagues report a trial of transurethral microwave hyperthermia in which actively treated patients were compared with a control group who received sham treatment (p 1293). ${ }^{3}$ Active treatment produced a significant symptomatic improvement but only a small and non-significant increase in flow rate, which was the measure of obstruction used. Although these new treatments probably work, they are considerably less effective than standard surgical treatment. To assess them we need measurements that can show not only that they work but also how they compare with the alternatives.

The symptoms produced by benign prostatic hyperplasia result from bladder outflow obstruction. ${ }^{2}$ The relief of obstruction is the aim of treatment, and effective treatment should produce objective improvement in measures of obstruction. The hallmark of obstruction is a reduced urine flow associated with an abnormally high voiding pressure. Although residual urine is not an accurate indicator of obstruction, a high residual volume after voiding, which improves after effective treatment, is an additional feature of the condition. In practice, measurement of voiding pressure is invasive and inconvenient, and, although rigorous assessment would demand its use, urine flow measurements alone are used in routine assessment and are the commonest objective measurement in trials of new treatments. Non-invasive measurement of residual urine volume by ultrasonography is frequently added. With the possible exception of prostatic stents, ${ }^{4}$ no method of treatment approaches transurethral prostatectomy (or open surgery) in improving these variables.

Patients, however, seek treatment not for abstract urodynamic concepts but for symptoms. Indeed, all urologists occasionally see the unhappy man still rising several times a night after his transurethral prostatectomy who fails to be impressed by his improved flow rate. Many men with prostatic symptoms are reluctant to submit themselves to surgery-hence the place for alternative treatments. Although the urologist would want objective evidence of the relief of obstruction, symptomatic improvement must also be documented. In most studies a system of symptom scoring is 